\title{
Cooperação no âmbito do ensino superior: ser estudante angolano em universidades portuguesas
}

\author{
Margarida Lima de Faria *
}

Resumo: No presente artigo desenvolver-se-á uma análise sobre o lugar desempenhado por Portugal na formação escolar superior de estudantes angolanos, procurando dar conta dos aspectos simbólicos, afectivos, culturais e económicos subjacentes a essa escolha. A análise incidirá, ainda, sobre uma caracterização sociológica das trajectórias educacionais e socioeconómicas das suas famílias, e destas por relação com a estrutura social angolana em situação de mudança. Procurará ainda cruzar a trajectória dessas famílias e o valor atribuído ao capital escolar com a trajectória de Angola e o investimento no ensino, desde o período da independência. Esta caracterização, quer dos estudantes quer das famílias, far-se-á igualmente por relação com outras situaçôes sociais, por esses grupos entendidas como "outras". Nesta última abordagem, procurar-se-á analisar a forma como esses estudantes representam as "elites no poder" e, ainda, como essa representação interfere nas suas expectativas em relação ao futuro, nomeadamente no que se refere ao retorno ao seu país.

Palavras-chave: formação avançada; migração; elite; cooperação; Angola.

\section{Cooperative policies in higher learning: being an Angolan student at Portuguese universities}

Abstract: The author analyses Angolan students' higher education while studying in Portugal, by taking into account the symbolic, affective, cultural and economic aspects influencing the choice of studying that country. The analysis will also characterize educational and socioeconomic routes defined by the students' families, as well as their relations to the current social changes taking place in Angola. One of these changes is the increased value given to higher education, specifically after independence. The national intervention in this area is related to the families' investment in a dialectic discussion between short-term individual actions and long-term structural changes. It is hypothesized that the value given to education depends on individual socio-economic and political positions. This idea is reinforced by the analysis of the way students interviewed conceive other groups of students who chose other countries for higher education, as well as the way they see themselves in relation to the current Angolan elite.

* Investigadora auxiliar do Programa de Desenvolvimento Global, Departamento de Ciências Humanas, Instituto de Investigação Científica Tropical - IICT, Lisboa, Portugal. margaridalf@iïct.pt 
Finally we discuss how they see their future and their expectations concerning their return to Angola, after obtaining their diploma.

Key words: advanced education; migration; elite; cooperation; Angola.

\section{Introdução}

Portugal vem, desde 1975, recebendo nas suas universidades estudantes de países africanos de língua oficial portuguesa que se inscrevem em cursos superiores, pós-graduações, mestrados e doutoramentos. De acordo com estatísticas oficiais ${ }^{1}$, os estudantes angolanos são os mais representados desse conjunto de países (Pessoa, 2004, p. 1).

A construção de cadeias de significados relacionados com a experiência de vivência fora do país - e, no caso presente, com a experiência desses jovens angolanos em Portugal - é um processo dinâmico, de características únicas para uma geração, desenrolando-se em contextos espaciais e temporais próprios, independentemente das políticas de integração ou das narrativas de identificação que as enquadram.

Cada geração cria para si mesma as suas condições de recepção e assimilação de situações de contacto com a diferença, sendo também livre para atribuir sentidos aos acontecimentos e para reler, de modo próprio, passados e raízes culturais comuns.

Partindo desses pressupostos, começar-se-á por discutir a importância da mobilidade para a prossecução de estudos superiores, em termos das expectativas à partida, das possibilidades de escolha, assim como do modo como esta situação contribui para a reconfiguração da posição social, sobretudo para aqueles que têm como expectativa o regresso ao país de origem.

De seguida, procurar-se-á discutir o conceito de "elite", tal como este se apresenta na literatura sociológica, abordando a importância da posse de capital escolar, económico e simbólico na sua constituição e a forma como as "elites no poder" se vão configurando e alternando, em diferentes momentos da história recente de Angola.

Logo, analisar-se-á o modo como os estudantes angolanos a realizar estudos superiores em Portugal se vêem a si próprios nesse processo de constituição de

1. Os estudantes angolanos inscritos em estabelecimentos de ensino superior portugueses no ano lectivo 200 I-02 representam 33,9\% do total de estudantes dos países da Comunidade de Países de Língua Portuguesa inscritos nos mesmos estabelecimentos; seguem-se os estudantes de Cabo Verde, que representam 26,5\%; os do Brasil (16,2\%), Moçambique (11,4\%), GuinéBissau (5,8\%), S. Tomé e Príncipe (4,7\%) e Timor-Leste (I ,4\%). (Pessoa, 2004). Revista Janus, Anuário de Relações Exteriores, co-editado desde 1996 pelo jornal $P$ ÚBUCO e pela Universidade Autónoma de Lisboa. Base de dados da Direcção Geral do Ensino Superior (DGES). In: < http:/ /www.janusonline.pt.> 
elites angolanas e, até que ponto essa consciência de "si" os direcciona nas suas escolhas e na construção da sua visão de futuro. Ou seja, discutir-se-á a sua própria representação de "elite no poder", a sua representação de si como parte de uma qualquer forma de "elite", e o modo como essas diferentes representações interferem nos seus diferentes projectos pessoais, nos quais se inclui a escolha de Portugal e a possibilidade de regresso a Angola, obtido o diploma.

\section{Metodologia}

Foram realizadas 20 entrevistas com estudantes angolanos inscritos em cursos de educação avançada (licenciaturas, pós-graduações, mestrados e doutoramentos) em Lisboa e no Porto. Os estudantes entrevistados nasceram entre os anos de 1964 e 1987. Optou-se por um tipo de análise intensiva, tendo-se por isso escolhido a técnica de entrevista semi-estruturada ${ }^{2}$. Tentouse diversificar a escolha dos estudantes a inquirir, quer no que respeita ao curso e tipo de universidade (pública ou privada), quer mesmo no que respeita à origem social e consequente percurso de vida.

Ainda que evitando a ambição positivista de encontrar elementos estruturantes, dado que essa aspiração seria contrária à aceitação da complexidade e a uma disponibilidade para encontrar situaçôes imponderáveis, procuraram-se, contudo, elementos recorrentes que foram posteriormente organizados. Seguindo essa orientação, foi possível caracterizar os 20 jovens entrevistados do seguinte modo:

1. Jovens de famílias tradicionalmente pouco escolarizadas (minoria), mas com pais que se beneficiaram dos incentivos à educação no período pós-independência/ ou educaram os filhos nesse período.

2. Jovens de famílias cujo volume de capital escolar herdado é considerável (maioria) e que ao longo do seu percurso de vida desenvolveram um sentido estratégico direccionado para a sua valorização e reprodução, através da escolarização dos seus filhos.

3. Jovens de famílias cujo capital económico decorre da posse de capital escolar ou de actividades económicas de média dimensão; ou ligadas ao funcionalismo público com posições profissionais socialmente reconhecidas, embora não de topo (com uma dimensão residual na nossa amostra).

2. A amostra, no caso da investigação intensiva, não é tão rigorosamente representativa quanto a que tem por base um questionário, sendo também de dimensão mais reduzida. 


\section{2. "Mobilidades estudantis" para educação avançada e "mobilidades" das famílias}

A maioria das "histórias" das famílias dos estudantes que entrevistámos é marcada por sucessivas deslocaçôes, ora dentro do território angolano, ora direccionadas para o exterior. As deslocações para o exterior dirigem-se, na maioria dos casos, ainda que por vezes apenas temporariamente, para Portugal. Há quase sempre um ou outro elemento da família que viaja para esse país, numa dada fase do percurso de cada família ${ }^{3}$.

As razões que motivam (ou nalguns casos forçam) a mobilidade das famílias são de três ordens:

- Profissionais.

- Decorrentes dos conflitos armados (para protecção dos jovens e de parte ou toda a família nuclear).

- Educacionais (para a prossecução de estudos).

É sobre estas últimas que nos iremos debruçar.

A "mobilidade" é normalmente referida como sendo intrinsecamente "moderna", ainda que, no caso de Angola, em certas situaçōes e em momentos históricos particulares - e desde tempos recuados - configure-se como uma inevitabilidade, com repercussões importantes nos processos de mudança social e cultural. À mobilidade junta-se o investimento em formação escolar; no catapultar dos indivíduos para fora dos seus quadros cognitivos tradicionais, a formação escolar, ela própria, conduz (como veremos mais à frente) à concretização de estratégias de mobilidade.

A mobilidade é "moderna" pelo que significa de disponibilidade de negociação daquilo a que Pierre Bourdieu (1979) denominou do "campo dos possíveis" (as possibilidades de escolha que encontram ou criam para si próprios e através das quais definem e consolidam estratégias de vida) de cada indivíduo, ou família.

A importância que damos à "mobilidade" dessas famílias decorre, pois, do facto de as vermos como uma forma de agenciamento particularmente interessante, por resultar de escolhas que são elaboradas de forma mais ou menos individual (ou decorrentes de uma decisão do grupo familiar enquanto tal), mas com repercussões consideráveis em contextos sociais mais amplos. $\mathrm{O}$ nosso pressuposto teórico é que as possibilidades de escolha e as decisões de deslocação (e entre elas as que envolvem deslocação para educação avançada) se encontram em uma zona de confluência entre agência e estrutura (esta última como siste-

3. Veremos mais adiante que a escolha de Portugal para a educação superior se insere nesta situação de relação histórica com este país. 
ma de regras e recursos) sendo, por isso, especialmente úteis na caracterização de cenários sociais e culturais dinâmicos, como os que se vivem hoje em Angola. Correspondem ao que Norbert Elias (1993) designa por "processos de individualização" ou processos através dos quais os indivíduos criam as suas próprias biografias, adequando, no entanto, os seus comportamentos e acções aos ambientes sociais onde se vão, em cada situação, enquadrando. Esses "processos de individualização" que afastam os indivíduos dos seus contextos sociais primários são tanto mais necessários quanto maior é a densidade das relações sociais e mais amplas as cadeias de interacção em que se envolvem. Esses processos iniciam-se, historicamente, com a deslocação de zonas rurais para zonas urbanas.

[No seio de sociedades centralizadas e urbanizadas] A mobilidade dos seres humanos singulares, tanto no sentido local como também social, aumenta. A sua anterior integração inevitável e perpétua na família, no grupo de parentesco, na comunidade local e outros colectivos deste tipo, a adequação do seu comportamento, dos seus objectivos e das suas ideias à vida em tais colectivos e a sua natural identificação com estes é cada vez menor. (Elias, 1993, p. 144)

As sociedades modernas definem-se desse modo, cada vez mais, pela existência de sujeitos em processo de autonomia pelo alargamento das "possibilidades de individualização", ou alargamento de possibilidades de escolha, que se decidem por uma escala cada vez mais global. A frequência do ensino universitário é disso exemplo paradigmático.

\section{O valor atribuído ao capital escolar}

A história recente da sociedade angolana, no que se refere à educação escolar, reflecte a construção dessa crescente possibilidade de "individualização", num primeiro momento pós-colonial - a partir do qual se abriram novas possibilidades (ainda que reguladas pelo Estado) — e, logo, pós-socialista, abrindo-se mais à iniciativa individual e envolvendo estratos mais amplos da sociedade. Assim, com o atenuar da regulação estatal, nas últimas décadas, e a consequente progressiva liberalização do sistema político e económico, a responsabilidade das famílias, nas escolhas das trajectórias educativas dos filhos, tem vindo progressivamente a reforçar-se, sobrepondo-se às decisões estatais. $\mathrm{Ou}$ seja, num Estado que se vai configurando como progressivamente liberal, o capital económico e escolar dos grupos familiares, ou a sua "possibilidade de individualização", vai, concomitantemente, adquirindo uma importância crescente nas estratégias reprodutivas das mesmas. 
No contexto europeu, a constituição da classe burguesa escolarizada resultou de um trabalho de séculos e consolidou uma cultura autónoma que a distingue de outros grupos dominantes e que, de algum modo, se foi autonomizando do poder político. No entanto, as elites escolarizadas africanas são-no normalmente por via de situações históricas descontínuas - como é a passagem do período colonial versus período pós-colonial —, mais sensíveis e mais dependentes dos diferentes contextos de acção política. A importância atribuída pelo regime angolano, à formação escolar, acompanha processos de mudança política que se podem sintetizar da seguinte forma:

(i) um primeiro ímpeto de formação pós-independência, em que sobressaiu o sentido de serviço nacional, alicerçado numa ideologia massificante de alcance emancipatório ${ }^{4}$ (período socialista);

(ii) um período em que sobressaíram sentidos mais individualistas, mais elitistas, mais egoístas (a que já aludimos), em conformidade com o advento de uma tendência socioeconómica de configuração liberalizante, que levou ao fim da regulação do Estado e vem definindo a configuração política e económica dominante nesse país.

A partir de 1975 e durante toda a década de 1980, a formação dos jovens, desde a primeira infância (o pré-escolar), obedeceu a um padrão nacional, relativamente estandardizado, que pretendia dar resposta a uma avaliação de necessidades nacionais e era coerente com uma linha política marcada pelo centralismo de Estado. Os grandes recém-chegados ao ensino eram, neste período (e por ordem de importância): os não-brancos, as mulheres e as populaçôes rurais, isoladas e carentes de todo o tipo de infra-estruturas básicas. Aqui se enquadra o primeiro grupo por nós identificado (i).

Em Angola há uma velha frase que diz assim: "Em Angola rico não vai à escola". E nós como não éramos ricos, nós tínhamos de ir à escola. Isso incentivava-nos. Nós sempre sonhávamos em um dia estar nas esferas decisivas do país e para alcançar isso, nós tínhamos que estudar, tinhamos que nos esforçar, tínhamos que acatar o conselho dos nossos pais. (Sexo masculino-34 anos - LicenciaturaEntrevista 16).

Adoptando os modelos de outros regimes (como é o caso dos países de Leste e de Cuba), a "educação para todos" transformou-se numa "bandeira" do regime.

Eu dou graças a Deus. Eu tenho a consciência que se não fosse a independência eu não teria chegado aqui! Nunca! Não teria pisa-

4. Emancipação de uma população negra e mestiça a quem foi, durante o colonialismo, negado o acesso à educação. 
do na Universidade! Nem... podia estar na condição de outras pessoas que nem sabem o que é Universidade. Eu, graças a Deus, para mim a independência - a nivelpessoal-foi o melhor que me aconteceu! Independentemente dos outros males, eu tenho muito a agradecer. Nesse campo agradeço. (Sexo feminino-Doutoramento -42 anos - Entrevista 10).

É significativo como crianças oriundas de meios rurais carentes em infraestruturas básicas prosseguem os seus estudos obedecendo a esse ímpeto de alcance nacional. $\mathrm{O}$ ensino primário era, nesse contexto, fortemente politizado.

Nós tínhamos de cantar o hino quando chegássemos à escola, depois... tratávamos os professores por camarada, os colegas por camarada, tinhamos assim um estilo... quando entrasse alguém, tínhamos que nos levantare dizer 'bom dia camarada professora' ou' 'bom dia camarada director'. (Sexo feminino - 25 anos - Licenciatura-Entrevista 2).

Eu sou da geração que ainda defendia, com muito orgulho, os simbolos da nação. Hoje em dia há uma grande crise nesse sentido. Mas eu tenho muito orgulho em terpertencido a essa fase e tenho muito boas recordaçôes dessa fase. (Sexo masculino - 34 anos - Licenciatura - Entrevista 15).

Para uma das estudantes entrevistadas (hoje a realizar o doutoramento numa Universidade de Lisboa), o investimento que sua mãe (uma mulher sem formação, trabalhadora agrícola, pobre e mãe solteira) fez na sua escolarização desde criança, prescindindo de sua ajuda em casa, explica-se pela sua filiação política:

Mas a minha mäe era da $O M A^{5}$ ! (Sexo feminino - 42 anos Doutoramento - Entrevista 10).

Seguindo esse desígnio de permitir o acesso massificado à educação, rompendo com o atraso deixado pela dependência colonial e formando a consciência das novas gerações de "fillhos da nação", a prossecução de estudos avançados destinava-se, nesse período, sobretudo, a preparar quadros politicamente integrados, impondo-lhes as áreas consideradas pelo regime mais carenciadas e restringindo a escolha pessoal do curso.

Sustentada nesta realidade, foi definida a periodização do acesso ao ensino médio e superior de jovens de origem operária e camponesa, bem como o envio de vários jovens para realização da formação média e superior nos países socialistas, como forma, no dizer do Presidente do MPLA, "de garantia da firmeza

5. Organização das Mulheres Angolanas. 
da posição de classe dos novos intelectuais". Na verdade, apesar de não haver uma política estruturada de formação de quadros ajustada às estratégias de desenvolvimento do país, o governo de Angola promoveu desde a independência, em 1975, um conjunto de acções orientadas para a formação maciça de quadros ao mais alto nível, tanto dentro como no exterior do país. (José Januário, 2007, p. 89).

Essa escolha estava (na segunda metade da década de 1970 e durante toda a década de 1980) nas mãos do Instituto Nacional de Bolsas de Estudo Inabe- órgão oficial do governo angolano.

Depois do $6^{\circ}$ ano preenchia-se uma ficha na qual o estudante registava a sua opção. Mas a decisão final era do Ministério da Educação. Eu gostaria de ter cursado advocacia, mas impuseramme a Escola de Educação. (Sexo feminino - 45 anos Doutoramento- Entrevista 1).

Aos alunos que se destacavam eram atribuídas bolsas de estudo, concedidas, sobretudo, pelos países "amigos" ${ }^{6}$, com os quais Angola tinha acordos de cooperação, abrangendo indivíduos de grupos sociais que, de outro modo, nunca teriam directo acesso à formação escolar superior. Portugal ainda estava longe de ser uma possibilidade de escolha.

Nos anos 1980 não era toda a gente que podia vir para Portugal, nessa altura as pessoas candidatavam-se a bolsas de estudo e iam para os paises de Leste. (Sexo feminino - 25 anos - Licenciatura - Entrevista 2).

Deu-se, desse modo, um considerável alargamento da base social dos diplomados angolanos que passou a incluir indivíduos provenientes dos estratos mais baixos da estrutura social. Os privilégios antecipados foram, no entanto, mais de ordem simbólica (obtenção de capital social), com repercussões na obtenção de capital económico, pela aproximação ao poder do Estado, do que propriamente por aproximação à esfera académica. Nesse período da história de Angola, a diferenciação económica estava, para Cristina Rodrigues (2005), no centro da diferenciação social. É, de acordo com a autora, o "informal" que se impõe nas novas situaçôes de mobilidade social.

6. Segundo dados do Inabe (2006), durante esse período (1975-2005), cerca de 40 países, distribuídos pelos cinco continentes, participaram no esforço de formação de quadros angolanos, em que o grande destaque foi a República de Cuba, com cerca de 7.821 (49,7\%) do total dos quadros formados no exterior, seguida da Rússia, com 3.469 (22\%), e Portugal, com I. 149 (7,3\%). (Januário, 2007, p. 91). Ver, ainda, para o caso da República da Polónia, o estudo de Paulo de Carvalho (Carvalho, 2002). 
O informal permitiu a um conjunto de citadinos a acumulação e a recriação de redes de solidariedades e de reciprocidades, rompendo com algumas barreiras impostas relativamente à mobilidade social e pressionando cada vez mais a reformulação dos termos relativos às precedências e aos critérios de ascensão social (2005, p. 3-4).

De acordo com a lógica educacional de então, direccionada, como vimos, para uma formação acelerada de quadros, o governo angolano apostava sobretudo em cursos médios de sentido profissionalizante com uma duração curta, de 2 a 3 anos. O PUNIV, como é denominado o curso pré-universitário, foi para esse efeito criado em 1979. Ou seja, a aposta num investimento escolar longo, sancionada pela posse de um diploma, estava longe de ser aquela que daria acesso directo a situações de prestígio.

O fim da Guerra Fria e o desmoronamento da União Soviética, agravados pela guerra civil, resultaram numa nova descontinuidade estrutural, com consequências profundas para Angola.

Perante a falência do modelo económico centralizado, com a progressiva democratização e com a introdução relativamente recente de novos pressupostos sociais e económicos - nomeadamente a economia de mercado e a expansão da economia informal - reconfiguram-se novas formas de acesso e gestão dos recursos. (Rodrigues, 2005, p. 1).

O segundo tipo que identificámos (ii) corresponde a famílias cujo volume de capital escolar herdado é considerável, e que, ao longo do seu percurso de vida, desenvolveram um sentido estratégico direccionado para a sua valorização, através da escolarização dos filhos. Os seus membros são, em geral, escolarizados acima da média, e estão envolvidos em dinâmicas sociais mais longas e duradouras (transitando sem sobressaltos do período colonial para o período pós-colonial). Trata-se de famílias com características semelhantes às das elites escolares europeias e que, apesar do atravessamento de situaçôes críticas e ameaçadoras, nunca deixaram de dar especial prioridade ao investimento no percurso escolar dos seus filhos, assegurando, desse modo, a sua própria reprodução. Para esses jovens, a filiação e a genealogia constituem-se como factores determinantes na definição das suas trajectórias escolares; ou seja, prosseguem os seus estudos porque já os seus familiares o fizeram, e porque é esse o ethos cultural das suas famílias.

Temos aqui dois "processos de individualização" com referências históricas diversas: 
(i) por via de processos recentes que, longe de serem contínuos, derivam de momentos politicamente propícios;

(ii) por via de processos contínuos ligados a uma historicidade educativa incorporada pelas famílias.

Em ambas as situaçôes, a formação escolar tem repercussões na estrutura geral do país ao produzir um campo de formação especializada que poderá vir a ocupar posições de decisão. Esta formação especializada (e reconhecida como legítima) tem vindo a ser crescentemente valorizada, em virtude de uma maior abertura democrática e económica. A crescente competição económica criada pelos investimentos estrangeiros em Angola e a crescente inserção deste país no mercado global criam novas necessidades e novos incentivos à formação escolar especializada. As novas elites incluem cada vez mais profissões que produzem, manipulam e disseminam conhecimento e informação; assim, aqueles que controlam os fluxos financeiros internacionais tendem a controlar também as instituições de educação avançada. (Lasch, 1995).

\section{Formação escolar e a constituição de quadros ou elites}

O conceito de "elite" é, antes de tudo, um conceito de "excelência social" constituído "por todos quantos possuem qualidades e aptidões especiais que legitimam o seu poder" (Fonseca, 2003, p. 45). Trata-se, assim, de uma situação que tem implícito o reconhecimento social de qualidades e aptidões; ou seja, a pertença à elite é o resultado da sua representação social, enquanto tal. Como diz Norbert Elias, embora se nasça nobre, ser nobre constrói-se. O facto de um grupo ser reconhecido como superior leva-o a uma transformação subjectiva no sentido de assegurar a sua aproximação ao estatuto que lhe foi atribuído, de modo a assegurar que esse reconhecimento é merecido. A constituição das elites altera-se quando as condições relativas, que definem a situação desse grupo, por relação com os que lhes estão ameaçadoramente próximos, também se alteram. É, paradoxalmente, esse contínuo processo de substituição de elites que permite explicar o equilíbrio e a longevidade desse corpo social. É ainda da possibilidade de comparação que as elites retiram a sua superioridade. Ou, como refere Pierre Bourdieu (1979), retiram a sua distinção das relaçôes que estabelecem com os outros indivíduos - redefinindo a sua própria identidade e estabelecendo as modalidades dessa distinção - ou da constituição de "homologias" (estruturas, espaços ou campos sociais que interagem entre si, daí resultando reforço simbólico mútuo); como as que unem o campo escolar (o campo das colocações escolares e da legitimação dos diplomas escolares) ao campo das estruturas fundamentais do espaço social e, em particular, ao campo do poder (1989). 
O conceito de elite, quando cruzado com a posse de capital escolar, é, assim, um conceito eminentemente relacional, posto que se assenta em processos de identificação entre indivíduos, que se configuram em torno dos diversos tipos de diploma (por áreas de ensino), dos locais onde foram obtidos (numa hierarquia de regiōes, países, estabelecimentos de ensino) e no modo como o obtiveram (sistemas de classificação, capital investido). Trata-se, pois, de um conceito aberto que, ao contrário de "classe dominante", não tem uma abrangência exclusivamente económica, possuindo, em si mesmo, um dinamismo e uma temporalidade que o tornam complexo. Envolve uma avaliação valorativa, que corresponde a uma cotação dos elementos que a definem num dado mercado simbólico, que tem unicamente sentido para certos grupos, ainda que cada vez operando em ambientes mais amplos e mais densos. Ou seja, as elites tendem a ser cada vez mais educadas e móveis.

\section{Representação de "elite" para os estudantes angolanos}

Ainda que esses 20 estudantes pertençam a um grupo relativamente minoritário de jovens angolanos que atingiram o ensino superior e o frequentam num país europeu; ou seja, ainda que essa situação, só por si, lhes confira um lugar socialmente reconhecível e reconhecido de pertença a uma elite escolarizada - o qual não escolheram, mas que resulta das próprias dinâmicas sociais de distinção e classificação -, a pertença à elite angolana, ou mesmo a possibilidade de vir a dela fazer parte um dia, obtido o diploma, é por eles energicamente recusada. Atribuem conotações fortemente negativas a essa designação. Descrevem-na não como uma situação meramente social, mas como uma condição ética que ameaça a sua integridade, os seus valores morais. No entanto, não estão seguros de resistir a ela:

E sente que vai pertencer a uma elite, quando voltar?

Eu acredito que não, tenho a certeza que não!

Por quê? A palavra "elite" é uma palavra que considera pejorativa?

Tenho a certeza... Não, para mim não é pejorativa. Hmmm... é que a questão da... Hmmm... a questão componente... as características em torno das elites... não só de Angola, mas de qualquer país, vão contra... vão contra os meus pressupostos básicos: as minhas convicçôes morais, as minhas convicçōes de fé...

Mas pode ser uma elite de um tipo novo...

Bem, isto... Eu até disse uma coisa que eu disse mal. Eu disse "tenho a certeza que não", mas não posso dizer isso com certeza. Eu gostaria de permanecer uma pessoa..., porque veja, da mesma forma que eu 
tenho perspectivas profissionais eu tenho as minhas perspectivas espirituais também. (Sexo masculino-26 anos - LicenciaturaEntrevista 13).

Testemunhos deste tipo, repetidos em várias das entrevistas, reflectem uma apreciação condenatória das "elites no poder". O mesmo estudante, que recusou ser conotado com a elite, aceita, porém, que, para contribuir para o desenvolvimento de Angola, tenha de o fazer em articulação com esses mesmos grupos no poder:

Mas vou-lhe ser honesto com uma coisa, isto agora é uma questão que eu the vou dizer abertamente e é uma realidade: que os lugares... porque eu tenho amigos que já estão a trabalhar lá, tenho amigos meus que foram meus colegas do ensino de base e estão a trabalhar lá, então, ainda há muita influência... das elites nos cargos superiores, os cargos de topo, não é? Os cargos de decisão. Ainda são influenciados por estas elites. Então, não émeu objectivo ir contra isso, en quero fazer a minha parte. (Sexo masculino-26 anos - Licenciatura - Entrevista 13).

Nessa distinção entre o "seu” lugar e o dos "outros", há ainda a consciência de que o percurso estudantil que percorreram se assemelha ao de (parte) dessa mesma elite à qual recusam pertencer; sendo a obtenção do diploma uma via inevitável de acesso a algo que designam de "lado de lá"; um "lado de lá" que se tem construído, de acordo com a avaliação de outro estudante, contra o interesse público:

O governo é composto por figuras que um dia foram estudantes... Eu não sei o que será de mim amanhã. Mas se tiver de estar do lado de lá, eu quero estar do lado de lá, mas em defesa daquilo que épúblico. (Sexo masculino-34 anos - Licenciatura - Entrevista 15).

Trata-se, no entanto, de uma passagem que não querem que se concretize totalmente. Desejam manter a sua formação moral, continuando a servir princípios de alcance nacional, resistindo a deixar-se influenciar. $\mathrm{O}$ investimento na obtenção de diplomas constitui-se, deste modo, como uma profissão de fé, ainda que experimentando alguma incerteza quanto ao seu real valor, ou seja, quanto à concretização da sua posse em situações profissionais que a justifiquem, e/ou com o alcance colectivo que desejam.

A sua situação de escolarizados acima da média é, deste modo, vista pelos próprios com um misto de optimismo e pessimismo. 


\section{As razões da escolha de Portugal e a produção de uma identidade estudantil}

$\mathrm{Na}$ descrição dos percursos das famílias, é recorrente o facto da situação transitória de residência em Portugal durante a década de 1990 - do próprio ou de parte do grupo familiar -, sobretudo nos períodos mais críticos da guerra civil. Este fato sustentaria a escolha de Portugal mais tarde para a prossecução de estudos superiores, já que ali estavam montadas algumas estruturas de apoio familiares e logísticas. Portugal tinha sido, e continuava a ser, um "ancoradouro", onde, mais tarde ou mais cedo, um ou outro elemento da família iria um dia desembarcar. Alguns estudantes vieram mesmo no final do ensino secundário para ter mais facilmente acesso ao ensino superior ${ }^{7}$. Essas estruturas de apoio familiar, que se desenvolvem, sobretudo, em torno da habitação e de alguma supervisão, são descritas por alguns estudantes como correspondendo a uma atitude, sobretudo solidária, mais do que propriamente afectiva, tendo sido, em alguns casos, a primeira vez, mesmo, que conviveram com "aqueles" membros da família.

Primeiro fiquei em casa de uns primos de quem eu não gostava e fiquei dois anos com eles fizo $10^{\circ}$ e o $11^{\circ}$ ano fui viver para casa da minha avó que foi uma experiência muito má. (Sexo feminino21 anos - Licenciatura - Entrevista 12).

Para além desta ligação familiar, cultural e afectiva, há ainda outros factores que influenciam a escolha de Portugal:

(i) a facilidade linguística (ainda que este seja também o factor de ponderação negativa, dado que a escolha também poderá incidir, pelo contrário, em países anglófonos) ou, como refere Carvalho, aqueles em que "as línguas neles utilizadas são das mais usadas no mundo (e também na literatura científica)" (Carvalho, 2002);

(ii) o facto de essas infra-estruturas logísticas trazerem benefícios económicos óbvios;

(iii) a proximidade dos sistemas de ensino de ambos os países, minimizando os efeitos negativos da inserção. Esta proximidade é ainda estrategicamente reforçada pela inserção de alguns desses jovens na Escola Portuguesa de Angola, previamente ao seu envio para Portugal;

(iv) algum prestígio de que goza o ensino superior português, acrescido de representações de excelência associadas à formação de protago-

7. A questão das equivalências dos estudos realizados em Angola pelo governo português é um problema que ainda está por resolver. 
nistas da política nacional portuguesa (do Portugal democrático) que vêm reforçar esse sentimento de familiaridade, dando segurança aos estudantes e às famílias.

OISEG, acho que é uma das melhores faculdades de economia cá em Portugal, tem nome no mercado, de cásaíram muitos líderes portugueses como o Cavaco Silva, por exemplo, tem nome! (Sexo masculino - 23 anos - Licenciatura - Entrevista 11).

Sendo este um mercado aberto, Portugal compete, no processo de escolha, com Inglaterra, Estados Unidos, Brasil, África do Sul (entre outros) ${ }^{8}$. Alguns definem essas opções como obedecendo a "ondas", ou "modas", de dimensão simultaneamente temporal e de "classe".

Eu vim para cá e fui uma das primeiras estudantes de Lubango a vir para cá, da nossa escola, e este ano, só para ter uma ideia, vieram uns cinco ou seis estudantes, de uma vez. Ou seja, em princípio evoluiu a vinda para cá. Mas com a abertura dessa nova faculdade lá, e com a África do Sul a ficar mais atractiva, falam inglês, as pessoas pensam: fazer uma licenciatura mas falando já inglês já é uma vantagem, mais acrescida. É preferivel do que vir cá para Portugal. Depois a África do Sulé um pais que é relativamente desenvolvido. Até se compararmos com Portugal até não está assim muito distante. Até se calhar até está superior em algumas coisas, não é? Por isso é uma boa aposta e normalmente as pessoas vão para a África do Sul. (Sexo feminino - 21 anos - Licenciatura - Entrevista 12).

Há, nesta mudança, uma aproximação aos centros decisórios da globalização:

Agora, por exemplo, os "ricalhaços" estão a pôr os filhos a estudar em Londres ou nos Estados Unidos, mas há questão de cinco anos atrás punham cá. Conheço um ou dois estudantes da classe alta. Mas é verdade, a maior parte da classe alta, ricos, entre aspas, já não vêm para Portugal. Há um tempo vinham todos, mas agora vão todos para Londres, Estados Unidos e alguns para o Brasil. (Sexo masculino - Licenciatura - 23 anos - Entrevista 18).

Para distinguirem-se desses estudantes "outros", dos que vão estudar em Londres, avaliam-nos como sendo fraco o seu investimento em capital escolar, dado que dele não necessitam, por serem herdeiros de quantidades consideráveis de capital económico.

8. De acordo com a leitura dos próprios estudantes entrevistados.

Pro-Posições, Campinas, v. 20, n. 1 (58), p. 45-63, jan./abr. 2009 
São pessoas que como o pai tem muito dinheiro não vale a pena estudar, não valorizam muito os estudos. E não tiveram aquela força de vontade de vir para cá estudar. Acho que aqueles que os pais têm assim menos posses são os que estão mais interessados em estudar. Depois acabam por ficar meio limitados porque não podem ir muito além. (Sexo feminino - Licenciatura - 21 anos - Entrevista 12).

Essa experiência de alteridade é também referida por Ana Bénard da Costa na análise que faz da vivência identitária de estudantes moçambicanos em Portugal.

Para muitos deles, esta vivência em Portugal é também uma nova vivência de si próprios, na medida em que tomam consciência daquilo que os distingue dos muitos "outros" com os quais interagem. (Costa, 2009).

Portugal é, desse modo, a "escolha" feita por um certo tipo social de estudantes de ambições médias, para quem é importante o capital escolar herdado (seja ele de longa ou de recente constituição). A escolha de Portugal como país de formação enquadra-se na estratégia de reprodução das famílias que procuram, por intermédio dos filhos, melhorar a sua posição pela manutenção ou pelo reforço desse capital.

O grupo em relação ao qual têm maior necessidade de se afirmar como diferentes é o das famílias que, possuindo grandes volumes de capital económico, entendem o capital escolar como marginal na educação dos seus filhos. Nessa comparação, para além das vantagens simbólicas relativas à posse de diplomas, atribuem a si próprios valores distintivos de coragem e de esforço:

São pessoas que como o pai tem muito dinheiro acham que não vale a pena estudar, não valorizam muito os estudos. E não tiveram aquela força de vontade de vir para cá estudar. Acho que aqueles que os pais têm assim menos posses são os que estão mais interessados em estudar. Depois ["os outros"] acabam por ficar meio limitados porque não podem ir muito além. (Sexo feminino - 21 anosLicenciatura - Entrevista 12).

\section{O regresso a Angola}

Escolhemos não discutir (no plano teórico) a problemática do regresso de indivíduos qualificados ao país de origem - brain drain - por razôes de estruturação (e dimensão) deste texto, embora se trate de um tema particularmente interessante pelas suas dimensões: económica e política; nacional e glo- 
bal. O não-regresso de "recursos humanos qualificados" é tido como "um dos muitos entraves humanos ao desenvolvimento" dos países africanos (Ferreira; Lopes; Mortágua, 2008).

Todos esses 20 estudantes que vieram para Portugal (e acentuamos a escolha do país, pois, como vimos, distingue-os social e politicamente dos que foram estudar, por exemplo, em Londres), ainda que tenham alguma suspeição em relação às elites do seu país - que os coloca de algum modo numa situação de outsiders -, quando postos perante a questão do regresso a Angola, obtido o diploma, dizem querer regressar um dia:

A maior parte regressa. Não digo que não há pessoas que vêm e ficam, mas a maior parte regressa. (Sexo masculino - 23 anos Licenciatura - Entrevista 18).

Essa é uma questão que temos discutido muito. Mas até aqui não encontrámos solução para esse caso. Uns defendem que o governo deve adoptar medidas de incentivo ao regresso dos quadros, eu não defendo esse princípio. Eu defendo o seguinte princípio: nós é que temos de nos imbuir do espirito de regressar e contribuir para o engrandecimento do país. Devemos antes perguntar o que é que nós podemos fazer por Angola e não o que Angola poderá fazer por nós. Eu acho que é a única maneira de podermos, [...] (Sexo masculino -34 anos - Licenciatura - Entrevista 15).

Encontrando-se numa zona intermédia entre os grupos no topo e os que estão mais próximo da base da estrutura social, reconhecem-se como privilegiados; esta situação de privilégio justifica o retorno dos esforços neles investidos em acções que tenham alcance colectivo, que beneficiem o seu país.

Nós somos privilegiados. Nós temos de voltar para Angola, para dar a nossa contribuição, visto que nós tivemos esse privilégio. Temos uma espécie de responsabilidade acrescentada de, no nosso futuro, nós termos de ir para lá. (Sexo masculino - 25 anos Licenciatura - Entrevista 6).

Ainda que queiram regressar a Angola, foram incapazes de precisar quando e como. Alguns admitem a possibilidade de obtenção de bolsas de mestrado e/ ou de doutoramento, pós-doutoramento (dependendo do grau em que estão), prolongando a sua situação de estudantes-angolanos-em Portugal até o limite das suas possibilidades. 


\section{Conclusão}

A mobilidade é "moderna" pelo que significa de disponibilidade, de negociação de cada indivíduo ou família; ou seja, as possibilidades que encontram ou criam para si próprios e através das quais definem e consolidam estratégias de vida. As escolhas que acompanham os percursos escolares criam novas possibilidades, de forte valor simbólico; a "trajectória nómada estudantil", nas palavras de Neusa de Gusmão (Gusmão, 2007), dirigida para Portugal e que aqui se analisa, configura-se, desse modo, como um campo de intensa reformulação de identidades e de contactos com a diferença, reforçando um sentido de identidade "estrangeirada" de matiz europeia, que será reconfigurado no momento de retorno e de reingresso na sociedade angolana.

Como forma de superar todas as incertezas, a capacidade de reacção das famílias aos constrangimentos provocados pela falta de recursos básicos ou pela insegurança da guerra, indissociável de um trabalho de vigilância constante em relação ao percurso escolar dos filhos, permitiu-lhes, sobretudo nos casos de situaçôes menos conformes com as trajectórias desejáveis, desencadear estratégias para contornar esses obstáculos. Do ponto de vista sociológico, é particularmente interessante verificar como as decisôes familiares, na origem do envio dos estudantes para o estrangeiro, são o produto da agência humana, mais do que de causas estruturais.

Em que medida Portugal, na situação pós-colonial, vem, para esses estudantes, prolongando algum lugar preexistente? Prolongamento este ocasionado pelas inevitáveis raízes deixadas pelas gerações passadas, pelas pontes de sangue decorrentes dos cruzamentos entre portugueses e angolanos, dos quais resultou a distribuição de familiares pelos dois países, e pela criação de estruturas de apoio (nas quais eles próprios se apoiam) tanto "lá" como "cá"?Em que medida Portugal não será também, mais do que isso, algo que dificilmente controlará: um país europeu inserido em redes que dão acesso a outro tipo de oportunidades, redes de informação, redes cosmopolitas onde se cruzam as mais diversas experiências de mobilidade?

Portugal situa-se numa nova posição geo-estratégica, semi-periférica, tendo, na segunda metade da década de 1990, reencontrado, e reconfigurado, o seu posicionamento relativo no quadro europeu comunitário, conferindo-lhe, esta situação, novíssimas possibilidades de usufruir de novas ligações políticas, económicas e educacionais.

Em termos das suas políticas de cooperação internacional para o ensino superior, é hoje, com o tratado de Bolonha, sobretudo um país da Europa. Uma Europa que aposta na mobilidade e na equidade do ensino dos seus membros; mas, em simultâneo, um país da CPLP no interior do qual circulam 
estudantes dos países de influência linguística portuguesa.

As mudanças ocorridas, nas últimas três décadas, na estrutura económica e social de Angola abriram caminho para mecanismos de transmissão de um tipo diferente, tornando os títulos escolares, particularmente os superiores, bens com importância não desprezível no mercado do emprego.

Portugal talvez esteja a receber, comparativamente com outros países, os estudantes angolanos que melhor saberão aproveitar, e enquadrar, o capital escolar adquirido, dado o esforço investido em grande parte das trajectórias familiares. Se souber construir com Angola formas de colaboração bilateral, na área da educação superior, poderá ser também beneficiário, libertando-se da pressão culpada de país ex-colonizador que o configura normalmente como país que ajuda, mais do que como país parceiro.

Uma boa articulação entre o processo agencial de envio (ligado às estratégias individuais das famílias) e a construção de situações favoráveis à sua recepção (estruturas), que os integrem no espaço europeu, afigura-se da maior importância no acompanhamento desses jovens; com ganhos óbvios para ambos os países.

\section{Referências bibliográficas}

BOURDIEU, Pierre. La distinction - critique social du jugement. Paris: Les Editions Minuit, 1979.

CARVALHO, Paulo de. Estrangeiros na Polónia. Adaptação, estereótipos e imagens étnicas. Luanda: Editorial Nzila, 2002.

COSTA, Ana Bénard (2009) Estudantes moçambicanos em Lisboa: Dinâmicas identitárias e processos de mudança social e cultural. In: HAVIK, P.; SARAIVA, C. Novas fronteiras entre a História e a Antropologia. Estudos em homenagem a Jill Dias (no prelo).

ELIAS, Norbert. A sociedade dos indivíduos. Lisboa: Publicações D. Quixote, 1993.

FERREIRA, Eduardo; LOPES, Carlos; MORTÁGUA, Maria João. A diáspora angolana em Portugal. Caminhos de retorno. Cascais: Principia, 2008.

FONSECA, Maria Manuel Vieira da. Educar herdeiros - práticas educativas da classe dominante lisboeta nas últimas décadas. Lisboa: Fundação Calouste Gulbenkian, Fundação para a Ciência e a Tecnologia, 2003.

GUSMÃO, Neusa. Na terra do outro. Invisibilidade e presença de estudantes africanos no Brasil, hoje. In: CONFERENCIA INTERNACIONAL DA UNIDADE DE CULTURAS E LÍNGUAS AFRICANA E DA DIÁSPORA NEGRA (CLADIN), 1., 2007, Araraquara. Comunicação: Faculdade de Letras e SESCS, Araraquara, 15-17 de maio de 2007.

JANUÁRIO, José. Análise do potencial de retorno dos quadros qualificados angolanos em Portugal - os exbolseiros pós-independência. 2007. Dissertação (Mestrado em Desenvolvimento e Cooperação Internacional). Instituto Superior de Economia e Gestão - ISEG, Lisboa 
PESSOA, Inês. Estudantes do espaço lusófono nas universidades portuguesas. Janus Espaço online de relações exteriores, 2004. Disponível em: <http://www.janusonline.pt >. Acesso em: 18 de setembro de 2008 .

RODRIGUES, Cristina. Os desafios da urbanidade na África lusófona. In: CODESRIA. Lusofonia em África: historia, democracia e integração africana. Maputo: Codesria, 2005.

Recebido em 15 de julho de 2008 e aprovado em 26 de setembro de 2008. 